\title{
BARISAN SISI ALAS PIRAMIDA HEPTAGONAL
}

\author{
DESSY ANDRIANI $^{1}$, MASHADI $^{2}$, SRI GEMAWATI $^{3}$ \\ 1) FMIPA Universitas Riau,dessyandrianiok@gmail.com \\ 2) FMIPA Universitas Riau, mashadi.mat@gmail.com \\ 3) FMIPA Universitas Riau, gemawati.sri@gmail.com
}

\begin{abstract}
ABSTRAK
Barisan sisi alas merupakan barisan yang diperoleh berdasarkan susunan jumlah bilangan bulat pada salah satu sisi alas bangun ruang piramida atau limas. Dalam tulisan ini akan dibahas barisan sisi alas pada piramida heptagonal dengan membuat sketsa tiga dimensi. Sehingga diperoleh hasil tujuh barisan bilangan sisi alas piramida heptagonal. Jumlah barisan sisi alas pada piramida heptagonal sama dengan jumlah sisi pada bidang alas piramida heptagonal.
\end{abstract}

Kata kunci: barisan bilangan, barisan sisi alas , barisan sisi alas piramida heptagonal,

\section{Pendahuluan}

Barisan dan deret merupakan salah satu bagian dalam bidang ilmu matematika yang mempelajari tentang bilangan, [2] dan [7] mengatakan bahwa barisan adalah suatu fungsi dengan domainnya adalah himpunan bilangan asli dan daerah hasil adalah himpunan bilangan real . Sedangkan barisan bilangan menurut [1]merupakan suatu susunan bilangan yang dibentuk menurut suatu urutan tertentu, urutan tertentu yang dimaksud adalah urutan mulai dari suku pertama $U_{1}$, suku kedua $U_{2}$, suku ketiga $U_{3}$, dan seterusnya sampai dengan suku ke- $n$.

Beberapa referensi telah membahas tentang barisan bilangan diantaranya [9] yang membahas barisan aritmatika dan barisan geometri dan [1] yang membahas mengenai barisan bertingkat. Serta [3], [4], [5], dan [6] yang membahas barisan sudut, barisan sisi alas dan jumlah pada bidang alas piramida setiap tingkatnya pada piramida tetrahedron, piramida, piramida pentagonal dan piramida hexagonal.

Beberapa barisan yang diperoleh berdasarkan susunan bilangan bulat pada tetrahedron atau piramida segitiga. Perhatikan gambar dibawah: 


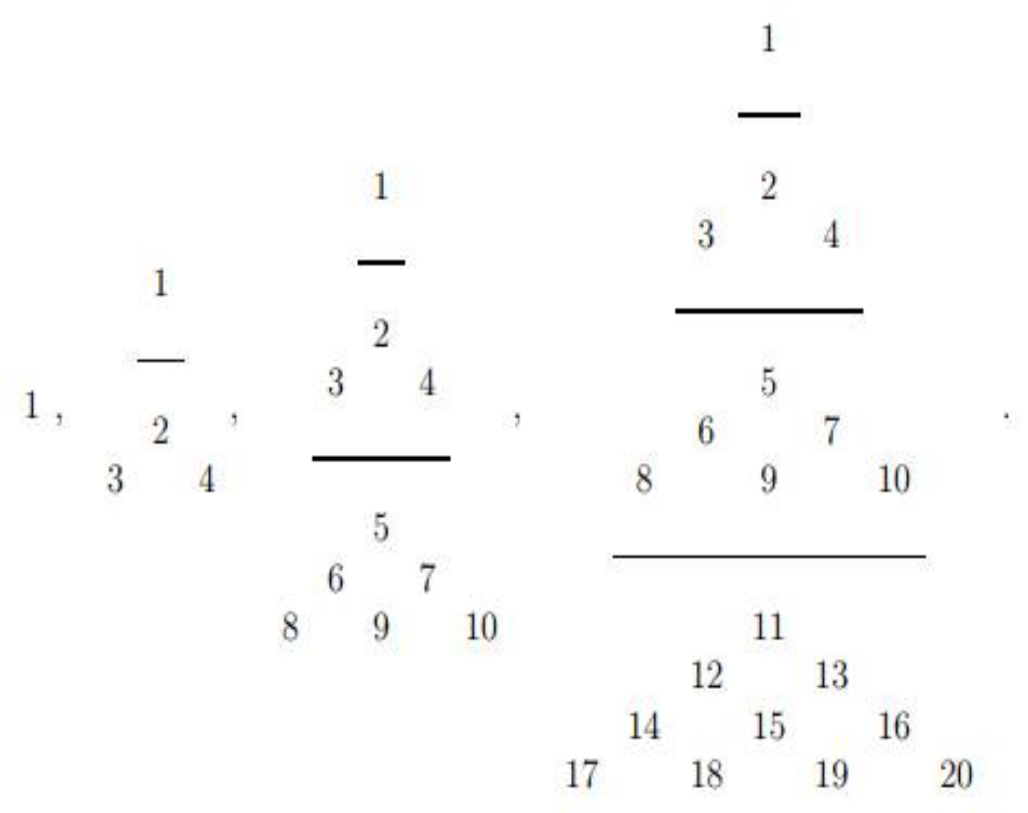

Gambar 1.Susunan bilangan bulat pada tetrahedron

Berdasarkan gambar 1 diperoleh beberapa barisan, yaitu barisan sudut, barisan sisi alas, dan barisan bidang alas setiap tingkatnya. Barisan sudut pada tetrahedron yang diperoleh [3] sebagai berikut:

$$
1,2,5,11,21, \ldots \quad s_{n}=\frac{1}{6}(n+2)\left(n^{2}-2 n+3\right)
$$

$$
\begin{array}{ll}
1,3,8,17,31, \ldots & s_{n}=\frac{1}{6}\left(n^{3}+3 n^{2}-4 n+6\right) \\
1,4,10,20,35, \ldots & s_{n}=\frac{1}{6}\left(n^{3}+3 n^{2}-4 n+6\right)
\end{array}
$$

selanjutnya [3]juga memperoleh barisan sisi alas pada piramida tetrahedron, yaitu:

$$
\begin{aligned}
1,5,19,54,125, \ldots & S_{n}=\frac{1}{6}\left(n^{3}+n^{2}-n+5\right) \\
1,6,22,60,135 \ldots & S_{n}=\frac{1}{6} n(n+1)\left(n^{2}+2\right) \\
1,5,7,27,74,165 \ldots & S_{n}=\frac{1}{6} n\left(n^{3}+3 n^{2}-n+3\right) .
\end{aligned}
$$

Barisan baru yang diperoleh [4]juga diperoleh menggunakan gambar sebagai berikut: 


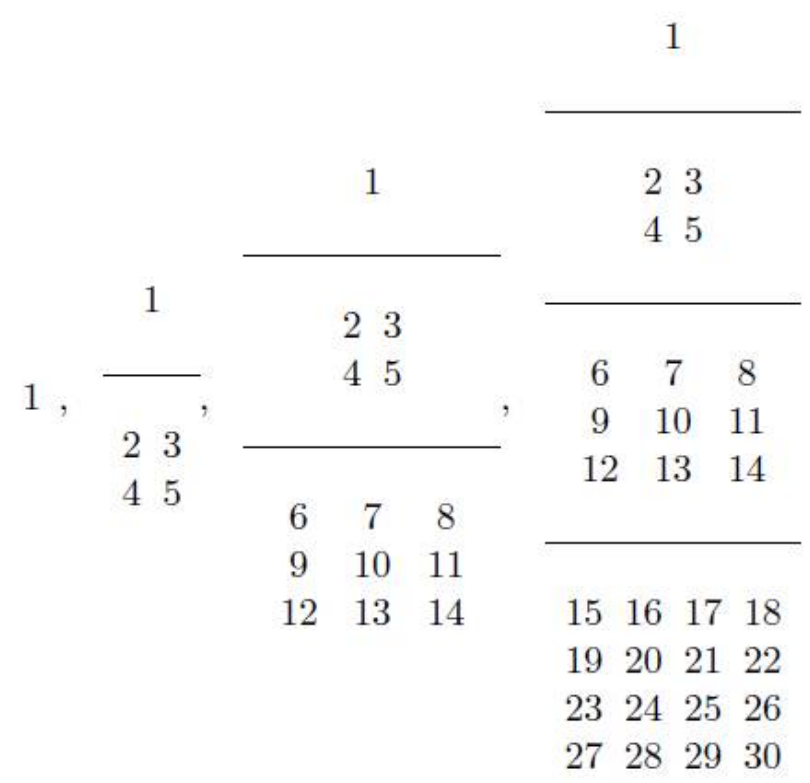

Gambar 2.Susunan bilangan bulat pada piramida

Berdasarkan Gambar 2 diperoleh beberapa barisan bilangan, diantaranya terdapat empat barisan sisi alas pada piramida, yaitu:

$$
\begin{array}{ll}
1,5,21,66,165, \ldots & S_{n}=\frac{1}{6} n\left(n^{2}+1\right)\left(n^{2}-n+3\right) \\
1,6,27,84,205 \ldots & S_{n}=\frac{1}{3} n\left(n^{3}-n+3\right) \\
1,8,33,84,205, \ldots & S_{n}=\frac{1}{3} n\left(n^{2}+3\right) \\
1,9,39,114,265 \ldots & S_{n}=\frac{1}{6} n\left(2 n^{3}+3 n^{2}-2 n+3\right)
\end{array}
$$

Dalam [5]membahas barisan bilangan yang dapat diperoleh pada piramida pentagonal, terdapat lima barisan sisi alas pada piramida pentagonal seperti berikut:

$$
\begin{gathered}
1,5,27,94, \ldots \\
1,7,39,130, \ldots \\
1,9,45,142, \ldots \\
1,11,51,154, \ldots \\
1,8,36,112, \ldots
\end{gathered}
$$

Lebih lanjut [6] membahas barisan pada piramida lainnya, yaitu barisan sisi alas pada piramida hexagonal. Berikut barisan sisi alas piramida hexagonal: 


$$
\begin{gathered}
1,5,31,114,305, \ldots \\
1,7,45,158,405, \ldots \\
1,9,52,170,425, \ldots \\
1,11,57,182,445, \ldots \\
1,13,63,194,465, \ldots \\
1,9,43,138,345, \ldots
\end{gathered}
$$

Selanjutnya [8] meneliti mengenai barisan sudut pada piramida heptagonal. Dalam artikel ini penulis membahas barisan sisi alas yang dapat dibentuk oleh piramida heptagonal beserta rumus umum suku ke- $n$ nya. Penelitian ini dilakukan dengan menggambarkan sketsa piramida heptagonal, dengan menggunakan konsep system persamaan linear diperoleh rumus umum suku- $n$ yang dibuktikan menggunakan prinsip induksi matematika.

\section{Barisan Sisi Alas pada Piramida Heptagonal}

Barisan sisi alas pada piramida heptagonal dapat diperoleh dengan melihat gambar piramida heptagonal tiga dimensi berikut: 


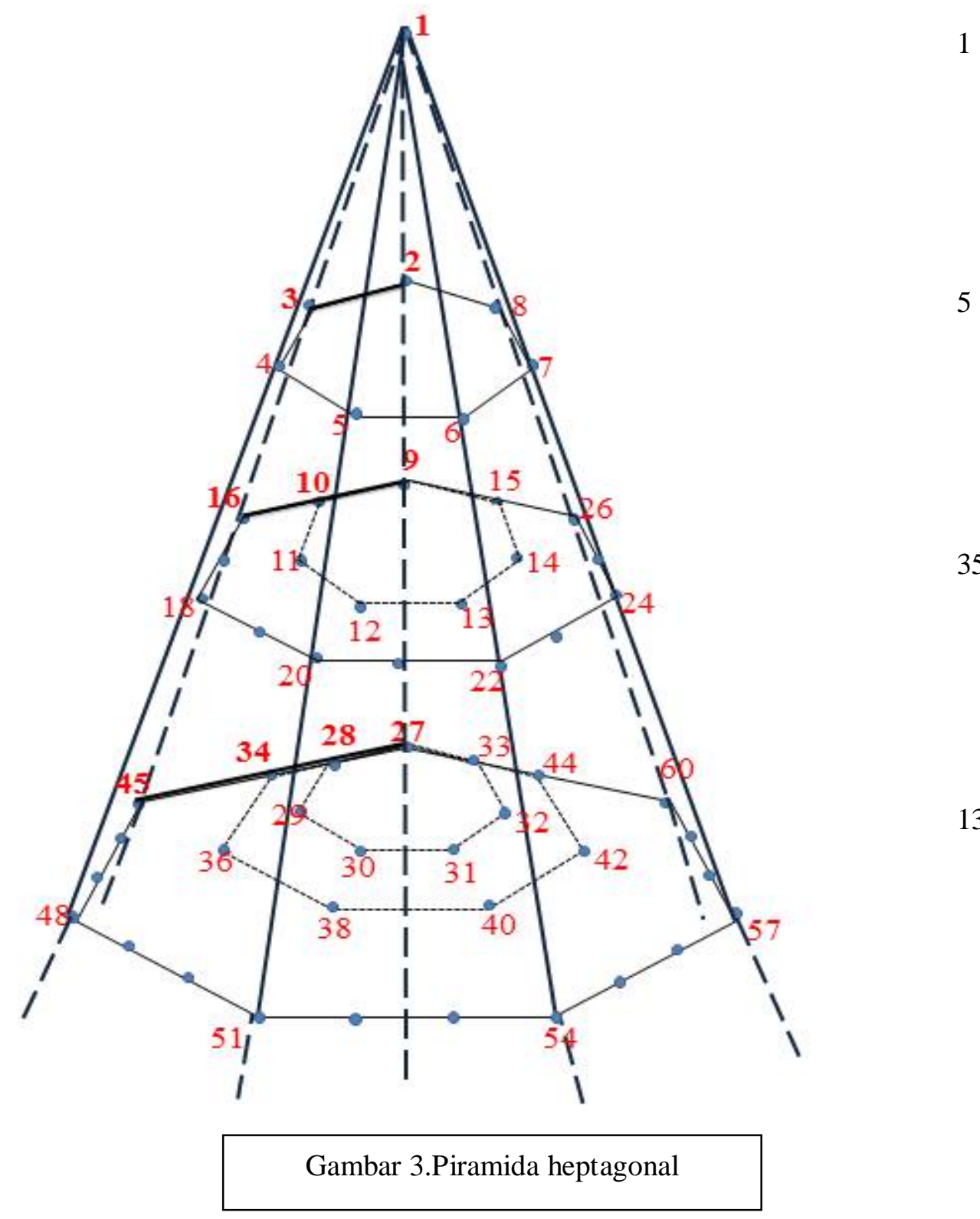

Dari hasil analisa piramida heptagonal pada Gambar 3, diperoleh barisan sisi alas pertama piramida heptagonal yaitu:

$$
1,5,35,134,365, \ldots
$$

Barisan sisi alas piramida heptagonal diatas merupakan barisan bertingkat, untuk menentukan rumus suku ke-nbarisan ke- $m\left(U_{(m, n)}(\mathrm{Hep})\right)$ dari barisan bertingkat terdapat dua cara yaitu dengan menggunakanpenjabaran binomial newton dan dengan sistem persamaan linear.

Cara 1: penjabaran binomial newton 


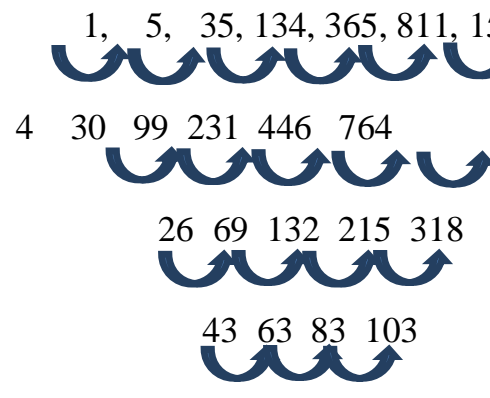

202020

Gambar 4. Barisan bertingkat pertama piramida heptagonal

$$
\begin{aligned}
\text { dengan } m_{1} & =1, m_{2}=4, m_{3}=26, m_{4}=43, m_{5}=20, \text { maka } \\
U_{(1, n)}(\text { Hep })= & \frac{m_{1}}{0 !}+\frac{(n-1) m_{2}}{1 !}+\frac{(n-2)(n-1) m_{3}}{2 !} \\
& +\frac{(n-3)(n-2)(n-1) m_{4}}{3 !} \\
& +\frac{(n-4)(n-3)(n-2)(n-1) m_{5}}{4 !} \\
= & \frac{1}{0 !}+\frac{(n-1) 4}{1 !}+\frac{(n-2)(n-1) 26}{2 !} \\
& +\frac{(n-3)(n-2)(n-1) 43}{3 !}+\frac{(n-4)(n-3)(n-2)(n-1) 20}{4 !} \\
= & 1+(n-4)+\left(n^{2}-3 n+2\right) 13+\frac{43}{6}\left(n^{3}-6 n^{2}+11 n-6\right) \\
& +\left(n^{4}-10 n^{3}+35 n^{2}-50 n+24\right) 5 \\
U_{(1, n)}(\text { Hep })= & \frac{1}{6}\left(5 n^{4}-7 n^{3}-5 n^{2}+13 n\right)
\end{aligned}
$$

Cara 2: sistem persamaan linear

Dari gambar 4 diketahui bahwa barisan tersebut berderajat empat, bentuk umum barisan berderajat empat akan di gunakan untuk menentukan rumus suku ke- $n$ barisan pertama $\left(U_{(1, n)}(H e p)\right)$ barisan sisi alas pertama piramida heptagonal seperti gambar berikut: 


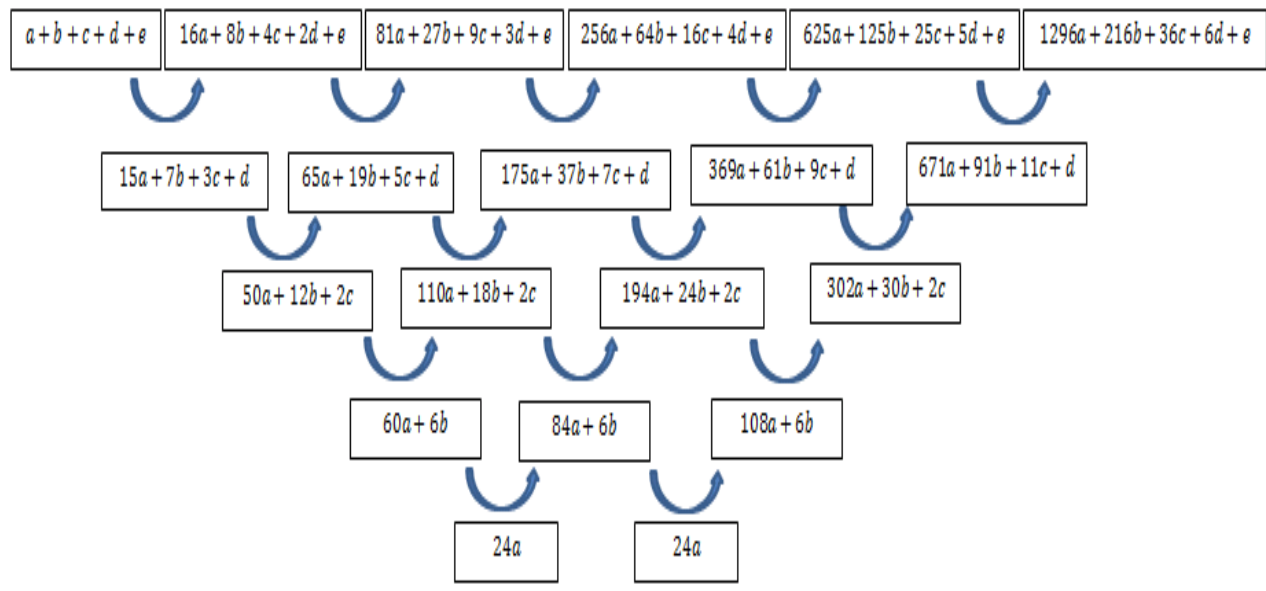

Gambar 5. Identifikasi selisih tetap barisan bertingkat empat

Dari gambar 4 diperoleh $m_{1}=1, m_{2}=4, m_{3}=26, m_{4}=43, m_{5}=20$. pada gambar 4 dan 5 diperoleh persamaan sebagai berikut:

$$
\begin{aligned}
& 24 a=m_{5} \\
& 60 a+6 b=m_{4} \\
& 50 a+12 b+2 c=m_{3} \\
& 15 a+7 b+3 c+d=m_{2} \\
& a+b+c+d+e=m_{1}
\end{aligned}
$$

Menggunakan perhitungan aljabar maka dari lima persamaan (1), (2), (3), (4), (5) diperoleh nilai $a=\frac{5}{6}, b=-\frac{7}{6}, c=-\frac{5}{6}, d=\frac{13}{6}, e=0$. Sehingga rumus suku kenbarisan $\quad 1, \quad 5, \quad 35, \quad 134, \quad 365, \quad 811, \quad \ldots \quad$ adalah $U_{(1, n)}($ Hep $)=\frac{1}{6}\left(5 n^{4}-7 n^{3}-5 n^{2}+13 n\right)$.

Teorema 1 (Barisan sisi alas pertama heptagonal) Untuk setiap bilangan bulat positif $n$ berlaku

$1+5+35+\cdots+\frac{5 n^{4}-7 n^{3}-5 n^{2}+13 n}{6}=\frac{4 n^{5}+3 n^{4}-14 n^{3}+9 n^{2}+22 n}{24}$ 
Teorema 2 (Barisan sisi alas kedua heptagonal) Untuk setiap bilangan bulat positif $n$ berlaku

$$
\begin{array}{r}
S(1): 1+7+51+\cdots+\frac{5 n^{4}+3 n^{3}-29 n^{2}+27 n}{6} \\
=\frac{4 n^{5}+13 n^{4}-26 n^{3}-n^{2}+34 n}{24}
\end{array}
$$

Dengan cara yang sama, diperoleh juga barisan sisi alas piramida heptagonal dan bentuk umum barisan sisi alas piramida heptagonal suku ke-nbarisan ke- $m$ $\left(U_{(m, n)}(H e p)\right)$ berikut:

(ii) $1,7,51,186,485, \ldots$ atau $U_{(2, n)}($ Hep $)=\frac{1}{6}\left(5 n^{4}+3 n^{3}-29 n^{2}+27 n\right)$

(iii) $1,9,57,198,505, \ldots$ atau $S_{(3, n)}($ Hep $)=\frac{1}{6}\left(5 n^{4}+3 n^{3}-23 n^{2}+21 n\right)$

(iii) $1,11,63,210,525, \ldots$ atau $S_{(4, n)}($ Hep $)=\frac{1}{6}\left(5 n^{4}+3 n^{3}-17 n^{2}+15 n\right)$

(iv) $1,13,69,222,545, \ldots$ atau $S_{(5, n)}(\mathrm{Hep})=\frac{1}{6}\left(5 n^{4}+3 n^{3}-11 n^{2}+9 n\right)$

(v) $1,15,75,234,565, \ldots$ atau $S_{(6, n)}($ Hep $)=\frac{1}{6}\left(5 n^{4}+3 n^{3}-5 n^{2}+3 n\right)$

(vi) $1,10,50,164,415, \ldots$ atau $S_{(7, n)}(H e p)=\frac{1}{6}\left(5 n^{4}-7 n^{3}+10 n^{2}-2 n\right)$

\section{Kesimpulan}

Barisan permukaan piramida dapat diperoleh menggunakn sketsa tiga dimensi dan untuk mencari rumus suku ke- $n$ dapat menggunakan sistem persamaan linear. Kemudian diperoleh hasil tujuh barisan bilangan sisi alas piramida heptagonal. Jumlah barisan sisi alas pada piramida heptagonal sama dengan jumlah sisi pada bidang alas piramida heptagonal.

\section{REFERENSI}

[1] Y. Azrida, Mashadi, dan Gemawati. S.Barisan bertingkat, Prosiding Seminar Nasional dan Kongres IndoMS. FMIPA Universitas Riau, 12-21, 2014.

[2] R. G. Bartle and D. R. Sherbert. Intruduction To Real Analysis Tird Edition. New york, John Wiley \& Sons, Inc, 2002. 
[3] GulliverT.A.Sequences from Integer Tetrahedrons. Int. J. Pure and Applied Math, vol.1, 517-521. 2006.

[4] Gulliver, T.A. Sequences from Pyramids of Integers. Int. J. Pure and Applied Math, vol.36161-165, 2007.

[5] Gulliver, T.A. Sequences from Pentagonal Pyramids of Integers, Int. Math. Forum, vol.5, 621-628, 2010.

[6] Gulliver, T.A. Sequences from Hexaagonal Pyramids of Integers, Int. Math. Forum, Vol.6, 821-827, 2011.

[7] Mashadi dan Abdul H. Analisis I. Pekanbaru: UR Press, 2017.

[8] Putri, N. H. S. Mashadi dan Gemawati S. Sequences from Heptagonal Pyramid Corners of Integer, Journal's Title, Vol.13, 193-200, 2018.

[9] Thompson, B. S.Bruckner, J. B. dan Bruckner A. M. Elementary Real Analysis. New Jersey: Prentice-Hall, 2001. 